\title{
Terdiurnal signatures in sporadic $E$ layers at midlatitudes
}

\author{
T. Fytterer ${ }^{1}$, C. Arras ${ }^{2}$, and C. Jacobi ${ }^{1}$ \\ ${ }^{1}$ Institute for Meteorology, University of Leipzig, Stephanstr. 3, 04103 Leipzig, Germany \\ ${ }^{2}$ German Research Centre for Geosciences GFZ, Potsdam, Department Geodesy \& Remote Sensing, \\ Telegrafenberg, 14473 Potsdam, Germany \\ Correspondence to: C. Jacobi (jacobi@rz.uni-leipzig.de)
}

\begin{abstract}
Global Positioning System radio occultation measurements by the FORMOsa SATellite mission3/Constellation Observing System for Meteorology, Ionosphere and Climate satellites were used to analyse the behaviour of the signature of the terdiurnal tide in sporadic $E$ $\left(E_{\mathrm{S}}\right)$ layers at midlatitudes $\left(43-63^{\circ} \mathrm{N}\right)$. According to theory, the occurrence of $E_{\mathrm{S}}$ is expected when the vertical zonal wind shear, which is mainly owing to solar tides, is negative. 4 yr means, based on 3-monthly running mean zonal means from December 2006-November 2010, were constructed for the terdiurnal oscillation in the occurrence frequency of $E_{\mathrm{S}}$. Comparison of the results with VHF meteor radar observations of the terdiurnal tide and the $8 \mathrm{~h}$ oscillation in the vertical zonal wind shear at Collm, Germany $\left(51.3^{\circ} \mathrm{N}\right.$, $13^{\circ} \mathrm{E}$ ) shows a clear correspondence between the $8 \mathrm{~h}$ in $E_{\mathrm{S}}$ and in wind shear signature.
\end{abstract}

\section{Introduction}

The wind fields of the mesosphere/lower thermosphere (MLT) are strongly influenced by atmospheric solar tides. These are global waves with periods of a solar day and its subharmonics and are therefore named diurnal tide (DT), semidiurnal tide (SDT), terdiurnal tide (TDT), etc. The tides are excited by absorption of solar radiation in the lower atmospheric layers (troposphere, stratosphere) and partly by wave-wave interactions (Teitelbaum et al., 1989). The wind amplitudes are small (on the order of few $\sim \mathrm{cm} \mathrm{s}^{-1}$ ) near the region of forcing, but increase significantly with height due to the decreasing air density. They maximise in the MLT at midlatitudes (Hagan et al., 1995). At these altitudes, the tides are the most dominant dynamical feature. The amplitudes are of the order of the magnitude of the mean wind and exceed those of planetary or gravity waves. Therefore, solar tides play an important role in the global circulation and a more accurate knowledge would result in a better understanding of the dynamics in the MLT. At midlatitudes, the strongest tide is the SDT, but in October the TDT also reaches significant amplitudes of $10 \mathrm{~m} \mathrm{~s}^{-1}$ and more (Fytterer and Jacobi, 2011). Thus, and since the climatology of the TDT is less intensely investigated than that of the DT and SDT so far, the TDT should be considered for further investigations of the global dynamics.

Sporadic $E\left(E_{\mathrm{S}}\right)$ layers are thin clouds of enhanced electron density, at midlatitudes primarily occurring in summer. They generally form in the upper MLT (90-120 km), which is equivalent to the lower ionospheric $E$ region. According to wind shear theory (Whitehead, 1961) the forming process of $E_{\mathrm{S}}$ is influenced by Earth's magnetic field, the ion concentration and the vertical wind shear as well. Neglecting diffusion, the vertical velocity of the neutral gas and the electric force, the vertical ion velocity $w_{\text {Ion }}$ can be written as:

$w_{\text {Ion }}=\frac{r \cdot \cos I}{1+r^{2}} U-\frac{\cos I \cdot \sin I}{1+r^{2}} V$,

where $U$ and $V$ are the zonal and meridional wind component of the neutral gas, while $I$ describes the inclination of the Earth's magnetic field. The parameter $r=\left(v_{\text {Ion } / \mathrm{N}}\right.$. $\left.m_{\text {Ion }}\right) /\left(e \cdot B_{0}\right)$ includes the ion-neutral gas collision frequency $v_{\text {Ion } / \mathrm{N}}$, the ion mass $m_{\text {Ion }}$, the elementary charge $e$ and the total intensity $B_{0}$ of the Earth's magnetic field. Note that for deriving Eq. (1) Cartesian coordinates were used ( $x, y$ and $z$ point eastward, northward and upward, respectively), which differs from the usual notations in literature. Considering that $r \gg 1$ at atmospheric regions below $\sim 115 \mathrm{~km}$ (Bishop et al., 2003), the zonal wind is significantly more efficient at causing a vertical plasma motion.

Furthermore, the forming of $E_{\mathrm{S}}$ requires negative vertical wind shear (Eq. 1), whose main source is the solar tides, partly providing larger vertical wind gradients than the background wind. Considering wind shear theory tidal-like 
structures are expected in $E_{\mathrm{S}}$. Recent studies have shown from phase comparison of the SDT wind shear and $E_{\mathrm{S}}$ signature that the latter are most likely caused by the SDT (Arras et al., 2009). Therefore, it appears also promising to search for a relation between the TDT and terdiurnal oscillations in $E_{\mathrm{S}}$.

In the following we analyse the terdiurnal signature in VHF meteor radar winds and wind shear over Collm, Germany. The seasonal cycle of these amplitudes will be compared against the TDT signature in $E_{\mathrm{S}}$ obtained from Global Positioning System (GPS) radio occultation (RO) measurements by the FORMOsa SATellite mission-3/Constellation Observing System for Meteorology, Ionosphere and Climate (FORMOSAT-3/COSMIC). TDT phases as seen in $E_{\mathrm{S}}$ and wind shear will be compared as well.

\section{Measurements and data analysis}

The GPS RO technique is used here to analyse the behaviour of $E_{\mathrm{S}}$. The method bases on radio links between Low-Earth Orbiting (LEO) satellites and GPS satellites. We use FORMOSAT-3/COSMIC measurements, assuring global coverage as well as a high vertical resolution. Due to the low Earth orbits of the FORMOSAT-3/COSMIC satellites, the GPS satellites are nearly fixed with respect to them and are observed as setting or rising objects. During this occultation the GPS signal is modified according to the atmospheric refraction index, containing information about air temperature, air pressure, water vapour content and electron density. The first three parameters are mainly tropospheric disturbances and are negligible in the ionosphere. As a result one occultation provides a complete vertical profile of the electron density. By analysing the signal-to-noise ratio (SNR), it is possible to extract an $E_{\mathrm{S}}$ signature from the background noise (Wu et al., 2005).

The disturbances of the signal are caused by divergence/convergence of the radio wave, leading to a decreased/increased intensity of the received signal. For analysis, first the SNR is normalised by dividing the measured SNR by the respective mean SNR. In the next step a band pass filter is used, only accepting disturbances smaller than $5 \mathrm{~km}$ in height range to account for the thin structure of $E_{\mathrm{S}}$ layers. Furthermore, the standard deviation of the normalised SNR is calculated for each height interval covering a sliding window of $2.5 \mathrm{~km}$. Since $E_{\mathrm{S}}$ cause sharp gradients in the electron density within a few kilometres, the fluctuations have to be strong and show a sharp vertical gradient. Consequently, the standard deviation of the normalised SNR should exceed the empirically found threshold of 0.2 and rises above 0.14 between two adjacent intervals to be accepted as an $E_{\mathrm{S}}$ signature. Note that if the standard deviation rises above the limit 0.2 in more than 5 intervals, the profile is excluded from further investigations to avoid similar disturbances from other sources (Arras, 2010). The height of maximum devia- tion from the mean profile is regarded as the approximate altitude of the $E_{\mathrm{S}}$. Note that the real altitude is closely above (below) in $45 \%$ (55\%) of the cases (Arras, 2010). Assuming spherical geometry the $E_{\mathrm{S}}$ is located where the radio wave is most refracted (the tangent point), whose exact coordinates are calculated, using at least four GPS satellites.

The six FORMOSAT-3/COSMIC satellites are operating since summer 2006, but this study only considers zonal mean values from December 2006-November 2010. Therefore, the ROs of every longitude in the latitude range $43-63^{\circ} \mathrm{N}$ are used, with the mean latitude of the occultations within this interval at $51^{\circ} \mathrm{N}$ (Arras et al., 2008). The time interval includes 3 months and the reference month was taken as the second one of the interval.

As can be seen in Fig. 1, the available data are nearly uniformly distributed during the year, ranging around 10000 per month (30000 per season). Lower sample rates only occur in 2010, because satellites were out of contact or some new firmware was tested (CDAAC Team, 2012). But for constructing the climatology a sufficient amount of data still remains. To give an overview about the general characteristics of the detected $E_{\mathrm{S}}$, Fig. 2 shows the seasonal cycles of the total number of $E_{\mathrm{S}}$ (upper panel) and the occurrence frequency (lower panel). The latter one is the number of detected $E_{\mathrm{S}}$ divided by the respective number of RO and finally multiplied by the factor 1000 for more handy values. Averages over a sliding height interval of $11 \mathrm{~km}$, shifted by $1 \mathrm{~km}$, were calculated and the reference height was taken as the centre of the interval. The above mentioned time and vertical height intervals are used in every following plot concerning $E_{\mathrm{S}}$, unless explicitly stated. The behaviour of $E_{\mathrm{S}}$ number and occurrence frequency is quite similar, due to the equally distributed $\mathrm{RO}$ in the course of a year. In general, $E_{\mathrm{S}}$ rates maximise around $105 \mathrm{~km}$. In summer, more than $4500 E_{\mathrm{S}}$ per season and $11 \mathrm{~km}$ interval were detected. The respective occurrence frequency reaches values above 0.14 . This seasonal cycle is caused by the variations of the meteor rates (see Fig. 3, Haldoupis et al., 2007), in combination with the dynamics in the MLT. Significantly lower $E_{S}$ rates are observed below $90 \mathrm{~km}$ and above $115 \mathrm{~km}$, as well as from December until April. Therefore, in later discussions the shown maximum height is reduced to $115 \mathrm{~km}$, but the lower altitudes are still considered for comparisons with the radar measurements.

The meteor radar located at Collm, Germany $\left(51.3^{\circ} \mathrm{N}\right.$, $13^{\circ} \mathrm{E}$ ) has been nearly continuously in operation since July 2004 and the $7 \mathrm{yr}$ dataset from August 2004-July 2011 was used for analysing the vertical wind shear and the TDT. The radar operates at $36.2 \mathrm{MHz}$ with a pulse repetition frequency of $2144 \mathrm{~Hz}$, applying a transmitter with a peak power of $6 \mathrm{~kW}$ and a pulse length of $2 \mathrm{~km}$. The emitted VHF radio wave is either completely (overdense) or only partly (underdense) scattered by ionised meteor trails. The detection array includes five antennas, which are forming an asymmetric cross to act as an interferometer. This constellation allows, in combination with range measurements, the calculation of 


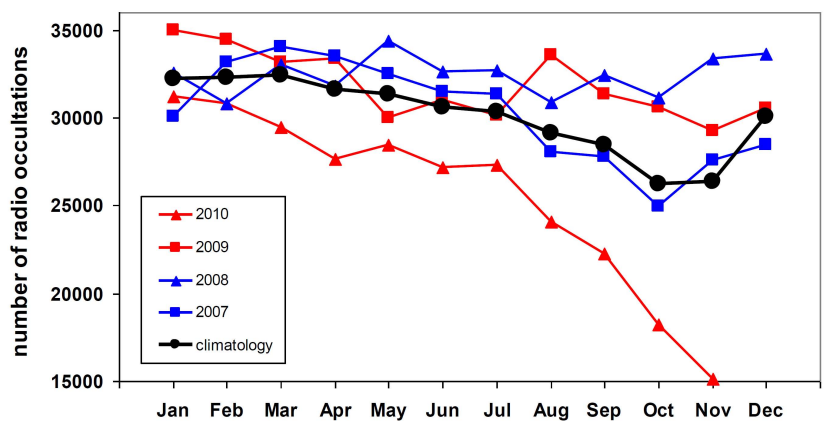

Fig. 1. Seasonal cycle of the number of radio occultations for a latitude range from $43-63^{\circ} \mathrm{N}$ measured by the FORMOSAT3/COSMIC satellites, using 3-monthly zonal sums from December 2006-November 2010.

the exact position of the detected meteor trail. The meteor rates vary strongly in time and space, peaking in summer and slightly below $90 \mathrm{~km}$, respectively (Fig. 3). The investigated height interval is divided into six non-overlapping height gates, binned at $82,85,88,91,94$ and $98 \mathrm{~km}$. Note that the real mean meteor height in the uppermost gate is only $97 \mathrm{~km}$ due to the decreasing rates with altitude (Jacobi, 2012). The radial wind velocity is obtained from the Doppler phase progression with time at each receiver. Horizontal halfhourly mean winds are calculated through projecting these mean winds on the individual radial winds and minimising the squared differences. An outlier rejection is added (Hocking et al., 2001). Half-hourly wind shears are calculated from the difference of the winds at two adjacent height gates.

Monthly mean winds and tidal $(8,12,24 \mathrm{~h})$ amplitudes and phases are calculated using a multiple regression analysis of the half-hourly mean winds as well as the wind shears. The procedure is described in detail in Jacobi (2012). Threemonthly running means are calculated using vector averaging for the phases and arithmetic averaging for the amplitudes.

\section{Results}

To investigate the structure of the $E_{\mathrm{S}}$ rates in more detail, the terdiurnal oscillation was extracted from the occurrence frequency (referred here as $8 \mathrm{~h} E_{\mathrm{S}}$ ) by using the same kind of multiple regression analysis, but on the global data which has been sorted according to local time. Previously performed frequency-wave number analyses (not shown here) have ensured that the westward migrating component is the dominant oscillation in $8 \mathrm{~h} E_{\mathrm{S}}$. Each fit includes the occurrence rates of 3 months and was applied for every month, while the time resolution was set to $1 \mathrm{~h}$. The height interval covers a sliding window of $11 \mathrm{~km}$, which is shifted by $1 \mathrm{~km}$.

At first, it should be validated that the calculated $8 \mathrm{~h} E_{\mathrm{S}}$ is not an artefact. Therefore, a closer look is taken at the occurrence frequency during October 2010 at $\sim 112.5 \mathrm{~km}$. Note that the following algorithm was performed for further al-
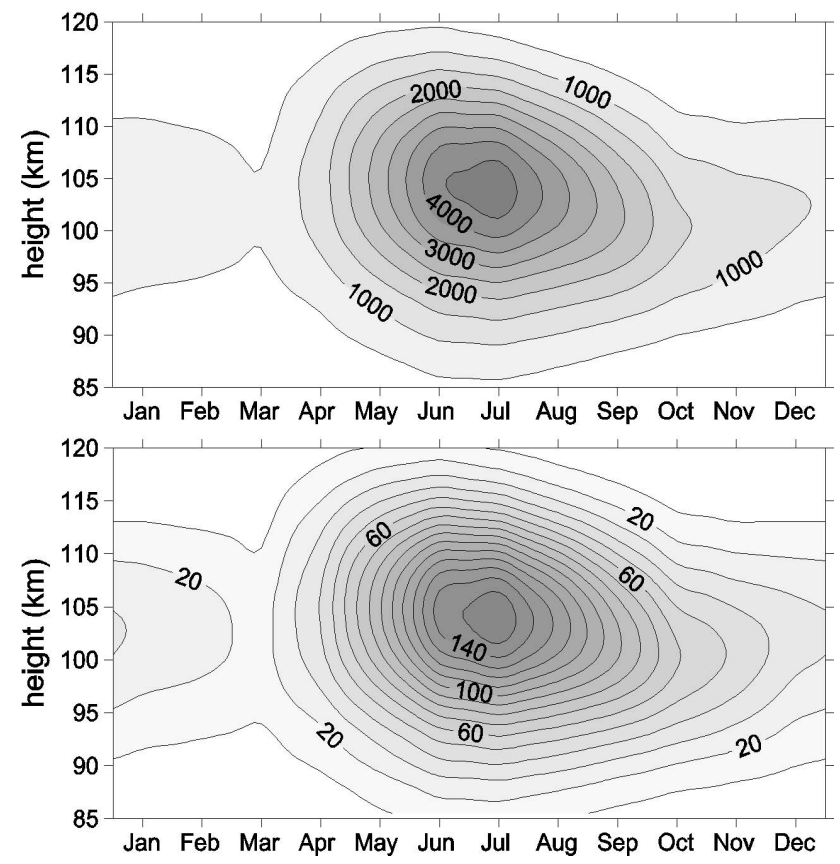

Fig. 2. Seasonal cycle of the total number of sporadic $E$ layers (upper panel) and the occurrence frequency (in 1/1000, lower panel) for a latitude range from $43-63^{\circ} \mathrm{N}$ measured by the FORMOSAT3/COSMIC satellites. Shown are 3-monthly running mean zonal means from December 2006-November 2010 with the height interval covering a sliding window of $11 \mathrm{~km}$ width, shifted by $1 \mathrm{~km}$.

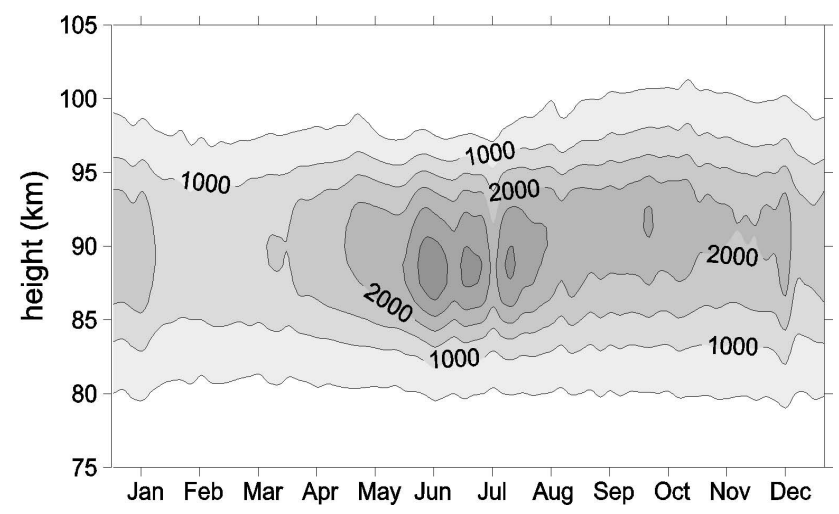

Fig. 3. Time-Height cross-section of the daily meteor rates detected by the meteor radar at Collm, based on the data from 2005-2010.

titudes and months from 2007-2010, which reveal similar results in principle. Figure 4 (left panel) shows the original measured occurrence rates and the respective modelled values. The used harmonic fit matches quite well with the observed occurrence rates, indicating that no further significant oscillations are present in the diurnal cycle of the $E_{\mathrm{S}}$ rates. However, no terdiurnal wave signature is visible, because the $24 \mathrm{~h}$ and $12 \mathrm{~h}$ waves are too dominant and have to be removed. Therefore, the harmonic analyse was used again, but excluding the $8 \mathrm{~h}$ oscillation. The resulting modelling 

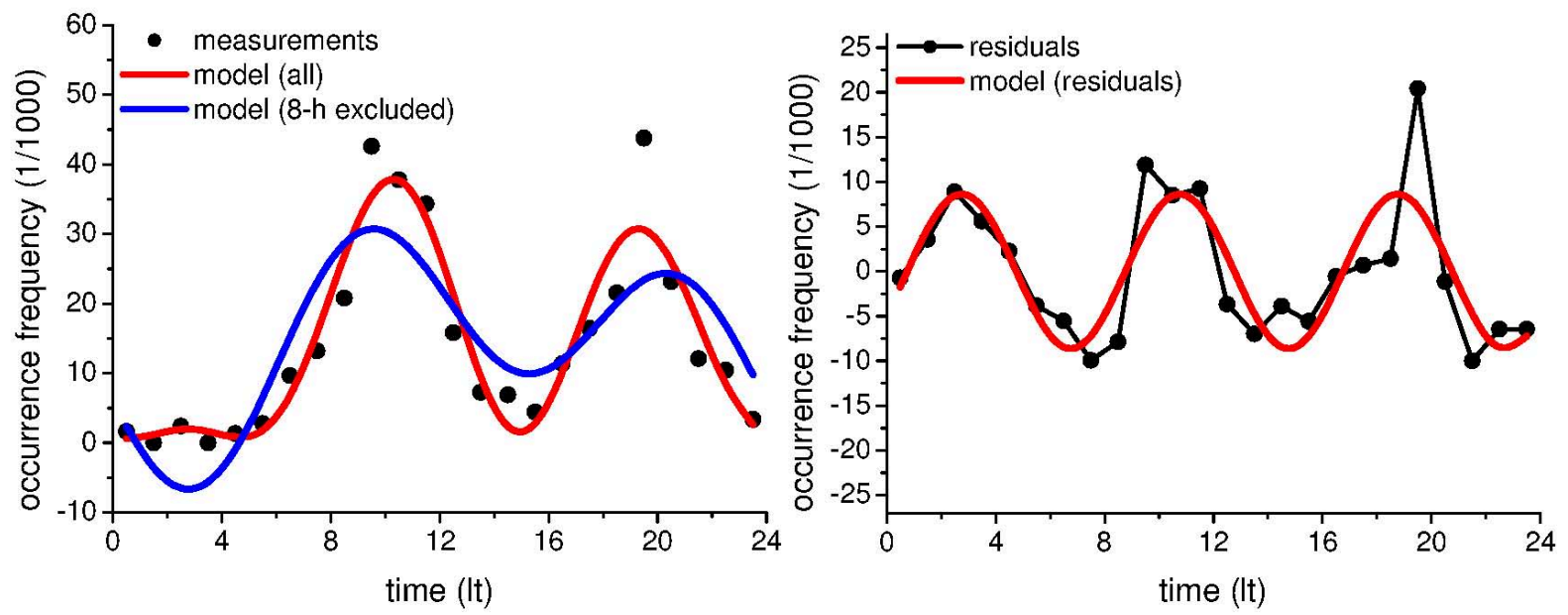

Fig. 4. Comparison of the measured occurrence rates with the respective model results at $\sim 112.5 \mathrm{~km}$ during October 2010 for a latitude range from $43-63^{\circ} \mathrm{N}$ (left panel). The right panel shows the filtered residuals versus the corresponding harmonic fit (only using $T=8 \mathrm{~h}$ ). Note the different scaling.

values were subtracted from the original measurements, providing the so called residuals (right panel). Here, a terdiurnal wave signature is apparent, which represents the measurements caused by the $8 \mathrm{~h}$ oscillation as well as further waves (e.g. $6 \mathrm{~h}$ wave...) and measurement errors. However, the terdiurnal wave is the most dominant feature in the residuals and is clearly evident, if the harmonic fit only including the $8 \mathrm{~h}$ oscillation is added. Note, that the shown fit is nearly identical with the same harmonic fit, which is applied for the original occurrence rates (not the residuals) and only includes the $8 \mathrm{~h}$ oscillation. Differences are only at the second position after decimal point.

Karami et al. (2012) also investigated $8 \mathrm{~h}$ signatures in $E_{\mathrm{S}}$, using ionosonde measurements from July 2006 to June 2007 over Tehran, Iran $\left(35.4^{\circ} \mathrm{N}, 51.2^{\circ} \mathrm{E}\right)$. Terdiurnal variations in the critical frequency and virtual height of $E_{\mathrm{S}}\left(f_{0} E_{\mathrm{S}}, h^{\prime} E_{\mathrm{S}}\right)$ were found in spring and summer as well as summer and winter, respectively, also indicating that the terdiurnal tidelike oscillation in $E_{\mathrm{S}}$ has a physical reason and is not a mere mathematical product.

The seasonal cycle of the amplitude of the $8 \mathrm{~h} E_{\mathrm{S}}$ signature, given in Fig. 5, reveals nearly no activity below $90 \mathrm{~km}$ and in winter, while the maximum occurs around $105 \mathrm{~km}$ during summer, reaching values above 0.022 . The corresponding occurrence rate is about $\sim 140 / 1000$, revealing that $22 / 140$ ( $\sim 15 \%$ ) of the $E_{\mathrm{S}}$ variability is caused by the $8 \mathrm{~h} E_{\mathrm{S}}$. In contrast to the occurrence rates, a secondary maximum is visible in late autumn $(>10 / 1000)$, where the $8 \mathrm{~h} E_{\mathrm{S}}$ influence increased to $10 / 40(25 \%)$. This indicates at least one additional $8 \mathrm{~h}$ signature source. Considering wind shear theory, the influence of the TDT is suggested, because the TDT reaches maximum amplitudes in autumn (Fytterer and Jacobi, 2011).

The observed seasonal behaviour is in good agreement with the results presented by Haldoupis and Pancheva

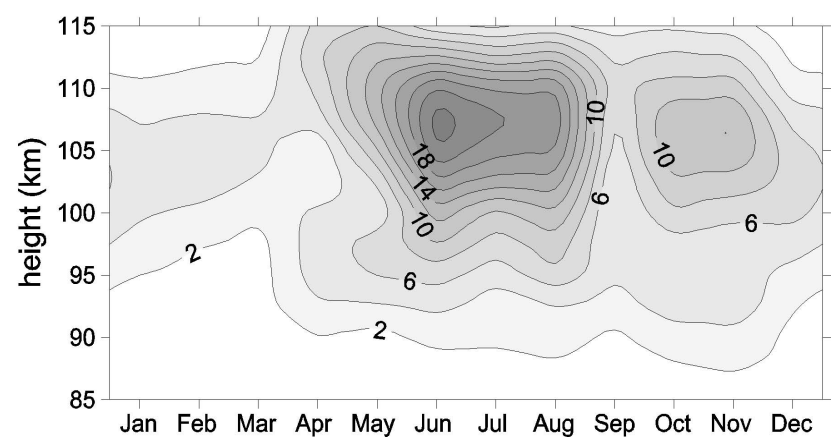

Fig. 5. Same as shown in Fig. 2, but for the amplitude (1/1000) of the $8 \mathrm{~h}$ oscillation within the occurrence frequency of the sporadic $E$ layers.

(2006), which investigated terdiurnal tide-like oscillations in the $f_{0} E_{\mathrm{S}}$, using the ionosonde at Rome $\left(41.9^{\circ} \mathrm{N}, 12.5^{\circ} \mathrm{E}\right)$. The analysed data included the years 1980-1991, but only the months May-October. However, the seasonal characteristics of the $8 \mathrm{~h} E_{\mathrm{S}}$ amplitude are strongly related to the behaviour of the occurrence frequency (Fig. 2, lower panel) and the dominating maximum in summer might be due to the higher $E_{\mathrm{S}}$ mean rates, which generally cause larger absolute fluctuations. Therefore, the influence of the background ionisation cannot be neglected and has to be excluded in further analysis.

The amplitude of the $8 \mathrm{~h} E_{\mathrm{S}}$ was normalised by dividing the $8 \mathrm{~h} E_{\mathrm{S}}$ amplitude by the respective 3-monthly mean zonal mean $E_{\mathrm{S}}$ occurrence rate. The results are presented in Fig. 6 (colour code) and were compared with the amplitude of the TDT (black isolines). The obtained normalised amplitudes do not show maximum values in summer any more, confirming wind shear theory as $8 \mathrm{~h}$ signature source. The 


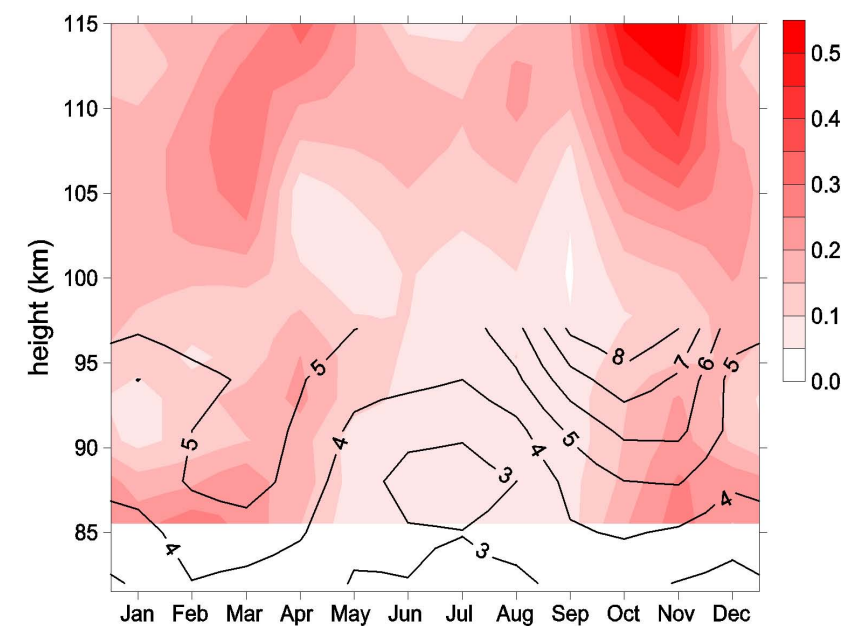

Fig. 6. Normalised amplitude of the $8 \mathrm{~h}$ oscillation within the occurrence frequency of the sporadic $E$ layers (colour code). Black isolines show the amplitude $\left(\mathrm{ms}^{-1}\right)$ of the terdiurnal zonal wind tide, measured by the meteor radar at Collm, using the data from August 2004-July 2011.

largest values are seen in October and November, reaching amplitudes of $\sim 0.5$ between $110 \mathrm{~km}$ and $115 \mathrm{~km}$. Also evident is a secondary maximum in spring, which is weaker by a factor of 2 . This seasonal cycle closely correlates with that of the wind TDT at lower heights, where the amplitude is also small during summer $\left(\sim 3-4 \mathrm{~m} \mathrm{~s}^{-1}\right)$ and maximise in October $\left(\sim 8 \mathrm{~m} \mathrm{~s}^{-1}\right)$ and March $\left(\sim 5 \mathrm{~m} \mathrm{~s}^{-1}\right)$, respectively. Note that the TDT amplitudes generally increase with height, while the $8 \mathrm{~h} E_{\mathrm{S}}$ amplitude decreases between $90 \mathrm{~km}$ and $100 \mathrm{~km}$, in particular during equinoxes. This may be due to the low $E_{S}$ rates (see Fig. 2) and the weak absolute amplitudes (Fig. 5), which means that small fluctuations can result in strong relative variations. This behaviour is not seen in summer. Furthermore, the maxima in both seasonal cycles are slightly shifted in time. However, a full agreement cannot be expected, due to the different observed height intervals.

Assuming that $E_{\mathrm{S}}$ are formed by the wind shear mechanism, the $8 \mathrm{~h}$ oscillation in the vertical wind shear (referred here as $8 \mathrm{~h}$ shear) was calculated and subsequently normalised by dividing the $8 \mathrm{~h}$ shear amplitude by the respective mean shear. In Fig. 7, the results of the normalised $8 \mathrm{~h}$ shear were compared with the normalised amplitude of the $8 \mathrm{~h} E_{\mathrm{S}}$. Note that the mean shear is sometimes very low, leading to very strong variations. These regions, occurring below $90 \mathrm{~km}$ in winter and above $94 \mathrm{~km}$ in summer, were excluded from further investigations (black shaded areas). Large negative values, which are observed in autumn $(\sim-3)$, imply a negative mean shear and comparatively large $8 \mathrm{~h}$ shear amplitudes. In general, negative amplitudes dominate from September-March, while positive ones are present in summer and late spring. This correlates with the seasonal behaviour of normalised $8 \mathrm{~h} E_{\mathrm{S}}$ as well as the amplitude of the

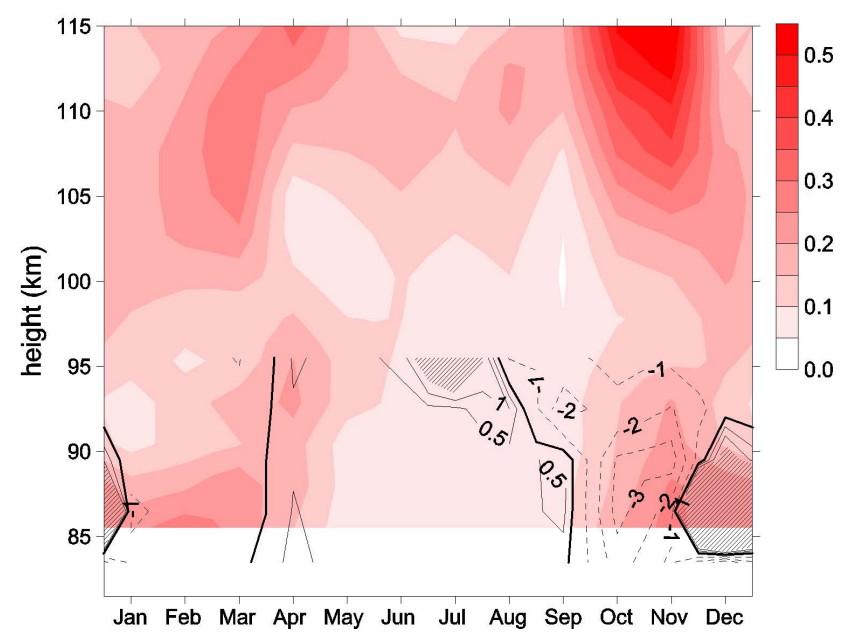

Fig. 7. Normalised amplitude of the $8 \mathrm{~h}$ oscillation within the occurrence frequency of the sporadic $E$ layers (colour code). The black isolines show the normalised amplitude of the $8 \mathrm{~h}$ oscillation in the vertical wind shear, measured by the meteor radar at Collm, while using the data from August 2004-July 2011. The zero wind shear line is highlighted and negative shear values are marked as dashed isolines. The isolines interval is 1 for negative and 0.5 for positive wind shear.

TDT. Note that the result corresponds to the wind shear theory, because during positive mean wind shear, tides can still provide a negative shear gradient.

To confirm the relation between the wind shear and the occurrence rates of $E_{\mathrm{S}}$, Fig. 8 shows the phases of the $8 \mathrm{~h}$ shear (squares) and the $8 \mathrm{~h} E_{\mathrm{S}}$ (circles). Note that the latter one is defined as the local time of maximum $E_{\mathrm{S}}$ probability, while the $8 \mathrm{~h}$ shear phase is given as the time of maximum negative wind shear. The seasonal means from 2007-2010 were vector averaged and the standard deviation (error bars) was calculated from the $4 \mathrm{yr}$ of seasonal mean data, which indicates the inter-annual variability. This was carried out for each $7 \mathrm{~km}$ height interval, using a $3 \mathrm{~km}$ overlap. The reference height was taken as the centre of the interval. Significant phases (filled symbols) of the $8 \mathrm{~h}$ shear occur generally between $86.5 \mathrm{~km}$ and $92.5 \mathrm{~km}$, except in winter. In summer and autumn, also the lowest or uppermost gates, respectively, show significant values. In contrast to that, the $8 \mathrm{~h} E_{\mathrm{S}}$ phases reveal only a few significant values, which were observed around $113 \mathrm{~km}$ in spring and slightly above $100 \mathrm{~km}$ during winter. However, in autumn, significant values are always present in the height interval $100-113 \mathrm{~km}$, suggesting the influence of the TDT.

Generally, the $8 \mathrm{~h} E_{\mathrm{S}}$ phases show a descending structure with time. This is according to theory (Haldoupis et al., 2006), where $E_{\mathrm{S}}$ layers follow the phase velocity of the tides, but this is the case only above $100 \mathrm{~km}$. In lower regions they slow down, due to the increasing ion-neutral gas collision frequency. A tendency for this can be seen in spring and summer, where the $E_{\mathrm{S}}$ phase is slightly bent around $100 \mathrm{~km}$. 

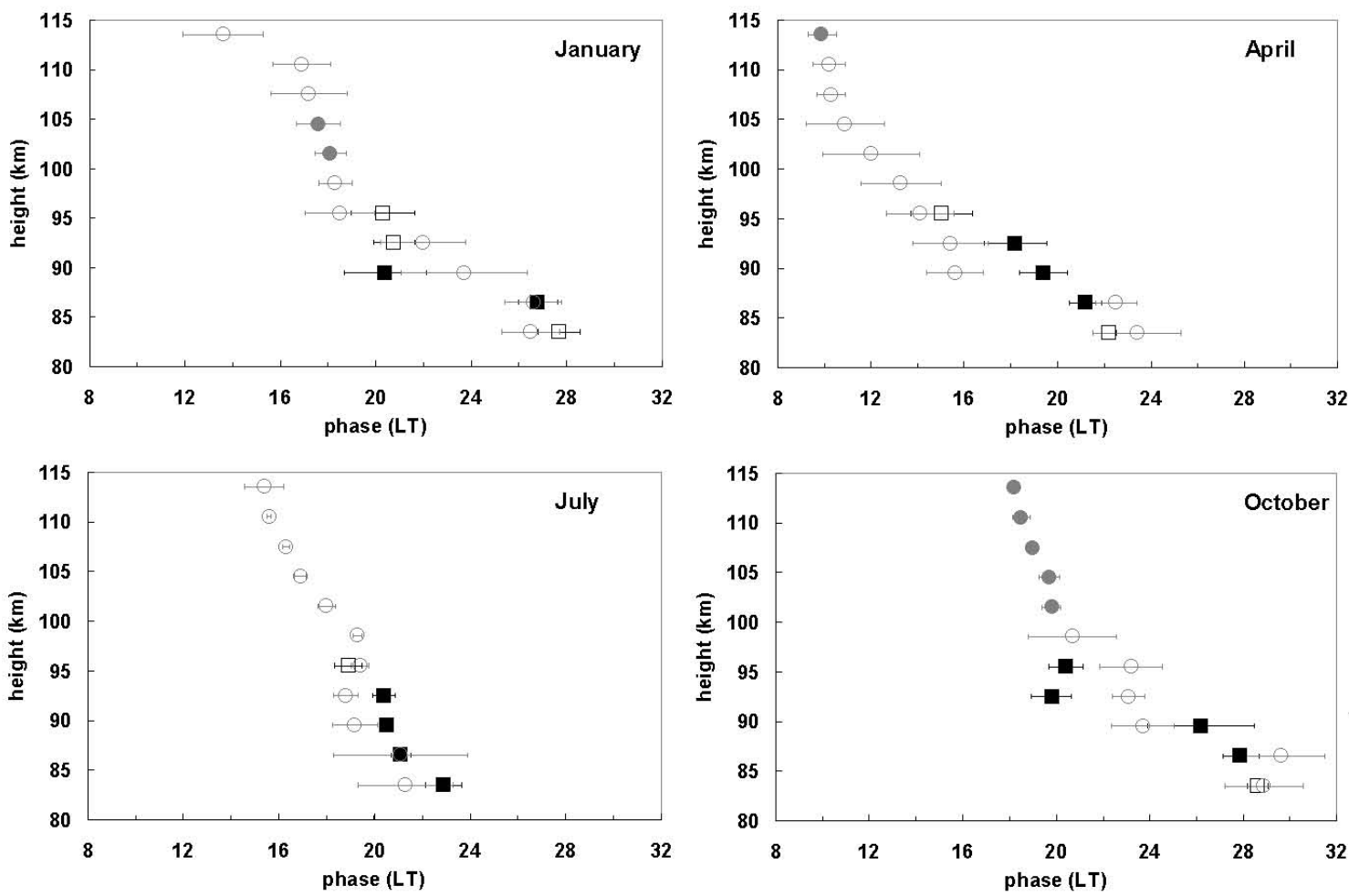

Fig. 8. Zonal component of the phases of the $8 \mathrm{~h}$ oscillation in the vertical wind shear (squares) and the sporadic $E$ layers (circles) for each season, based on 3-monthly running means from January 2007-October 2010. Filled symbols show significant phases according to a t-test. The error bars indicate the standard deviation of the individual seasonal mean values.

A bending in autumn and winter seems also possible, but it is, as indicated by the large error bars, not a regular feature. There are two reasons for these observations. On the one hand the GPS RO technique is not able to track a single $E_{\mathrm{S}}$. Consequently, fine-scale characteristics like the bending can only be seen in spring and summer, when a sufficient amount of $E_{\mathrm{S}}$ data is available. Furthermore, at lower heights $(<100 \mathrm{~km})$ some phase shifts occur, e.g., in autumn 2010 at $\sim 90 \mathrm{~km}$ or generally in spring at $\sim 95 \mathrm{~km}$ (not shown here), resulting in strong differences with respect to the expected values. Note that those described phase shifts are evident in $E_{\mathrm{S}}$ and wind shear data.

The vertical wavelength of the $8 \mathrm{~h}$ shear is short during spring (excluding the uppermost gate) and summer, but significantly longer during autumn and winter. This correlates with the behaviour of the TDT phases. However, the vertical wavelength of the TDT in $E_{\mathrm{S}}$ or wind shear is also dependent of the amplitude change with height and therefore cannot be directly compared with the wind amplitude phase gradient.

Although the majority of measured $8 \mathrm{~h} E_{\mathrm{S}}$ amplitudes is not significant, the general correspondence between the phases of $8 \mathrm{~h}$ shear and $8 \mathrm{~h} E_{\mathrm{S}}$ gives additional confidence that we observed a real phenomenon and not an artefact. The closest agreement between the phase profiles is seen in summer, although the TDT activity is low. In contrast, during autumn the agreement is less strong, while the TDT amplitudes are large. In spring and summer, an overlapping between the phase profiles was observed, and the extrapolated $8 \mathrm{~h}$ shear phases fit well with the $8 \mathrm{~h} E_{\mathrm{S}}$ phases in higher altitudes. Again, this is caused by the decreasing $E_{\mathrm{S}}$ rates below $100 \mathrm{~km}$ and the fact that the $E_{\mathrm{S}}$ phases are less strongly determined by the phases of the tides in theses regions. Lower $E_{\mathrm{S}}$ rates are also a reason for the phase shifts in some altitudes.

\section{Conclusions}

The terdiurnal oscillations in the occurrence frequency of $E_{\mathrm{S}}$ were analysed based on the measurements of the FORMOSAT-3/COSMIC satellites. The performed GPS RO technique does not allow tracking of a single $E_{\mathrm{S}}$, but information about the seasonal characteristics is available. Therefore, the 3-monthly running mean zonal means from December 2006-November 2010 were used for constructing $4 \mathrm{yr}$ means. After removing the effect of the background ionisation, we found that (1) the seasonal cycle of the normalised amplitude of the $8 \mathrm{~h} E_{\mathrm{S}}$ is marked by two maxima during spring and autumn, while the latter one is dominating. This agrees well with the seasonal behaviour of the $8 \mathrm{~h}$ amplitudes in wind and wind shear, which gives a strong indication for close physical connection between $E_{\mathrm{S}}$ and the TDT. We 
could also show that (2) the $8 \mathrm{~h}$ shear phases match the $8 \mathrm{~h}$ $E_{\mathrm{S}}$ phases (for the first time to our knowledge), which is the case especially when the $E_{\mathrm{S}}$ rates are high. Therefore, the $8 \mathrm{~h} E_{\mathrm{S}}$ is also forced or at least significantly influenced by dynamics. Furthermore the clearest signature of the $8 \mathrm{~h}$ shear is observed in autumn, correlating with the stronger TDT activity.

These qualitative correlations between the $8 \mathrm{~h}$ signatures in $E_{\mathrm{S}}$ and wind/wind shear were not expected, because the $8 \mathrm{~h} E_{S}$ oscillations based on zonal means, while the radar measurements of the wind field over Collm are affected by local phenomena. Therefore the results indicate that, according to wind shear theory, besides the well-known influence of the SDT also the TDT plays a role in the diurnal and seasonal cycle of $E_{\mathrm{S}}$. Further investigations considering other latitudes will be performed in future.

Acknowledgements. This study was supported by Deutsche Forschungsgemeinschaft under grant JA 836/22-1. We acknowledge UCAR (Boulder, U.S.) and NSPO (Taiwan) for the free provision of FORMOSAT-3/COSMIC data and related support. We also thank Falk Kaiser, Leipzig, for maintaining the radar measurements.

\section{References}

Arras, C.: A Global Survey of Sporadic E Layers based on GPS Radio Occultations by CHAMP, GRACE and FORMOSAT3/COSMIC, Ph.D. thesis, University of Leipzig, 127 p., 2010.

Arras, C., Wickert, J., Beyerle, G., Heise, S., Schmidt, T., and Jacobi, C.: A global climatology of ionospheric irregularities derived from GPS radio occultation, Geophys. Res. Lett., 35, L14809, doi:10.1029/2008GL034158, 2008.

Arras, C., Jacobi, C., and Wickert, J.: Semidiurnal tidal signature in sporadic $E$ occurrence rates derived from GPS radio occultation measurements at higher midlatitudes, Ann. Geophys., 27, 25552563, doi:10.5194/angeo-27-2555-2009, 2009.

Bishop, R. L. and Earle, G. D.: Metallic ion transport associated with midlatitude intermediate layer development, J. Geophys. Res., 108, A11019, doi:10.1029/2002JA009411, 2003.
CDAAC Team: http://cdaac-www.cosmic.ucar.edu/cdaac/status. html, last access: 26 June 2012.

Fytterer, T. and Jacobi, C.: Climatology of the 8-hour tide over Collm $\left(51.3^{\circ} \mathrm{N}, 13^{\circ} \mathrm{E}\right)$, Report of the Institute for Meteorology, University of Leipzig, 48, 23-32, 2011.

Hagan, M. E., Forbes, J. M., and Vial, J.: On modeling migrating solar tides, Geophys. Res. Lett., 22, 893-896, 1995.

Haldoupis, C. and Pancheva, D.: Terdiurnal tidelike variability in sporadic E layers, J. Geophys. Res., 111, A07303, doi:10.1029/2005JA011522, 2006.

Haldoupis, C., Meek, C., Christakis, N., Pancheva, D., and Bourdillon, A.: Ionogram height-time-intensity observations of descending sporadic E layers at mid-latitude, J. Atmos. Sol.-Terr. Phy., 68, 539-557, doi:10.1016/j.jastp.2005.03.020, 2006.

Haldoupis, C., Pancheva, D., Singer, W., Meek, C., and MacDougall, J.: An explanation for the seasonal dependence of midlatitude sporadic E Layers, J. Geophys. Res., 112, A06315, doi:10.1029/2007JA012322, 2007.

Hocking, W. K., Fuller, B., and Vandepeer, B.: Real-time determination of meteor-related parameters utilizing modern digital technology, Atmos. Sol.-Terr. Phy., 63, 155-169, 2001.

Jacobi, C.: 6 year mean prevailing winds and tides measured by VHF meteor radar over Collm $\left(51.3^{\circ} \mathrm{N}, 13.0^{\circ} \mathrm{E}\right)$, Atmos. Sol.Terr. Phy., 78-79, 8-18, doi:10.1016/j.jasp.2011.04.010, 2012.

Karami, K., Ghader, S., Bidokhti, A. A., Joghataei, M., Neyestani, A., and Mohammadabadi, A.: Planetary and tidal wave-type oscillations in the ionospheric sporadic E layers over Tehran region, J. Geophys. Res., 117, A04313, doi:10.1029/2011JA017466, 2012.

Teitelbaum, H., Vial, F., Manson, A. H., Giraldez, R., and Massebeuf, M.: Non-linear interactions between the diurnal and semidiurnal tides: terdiurnal and diurnal secondary waves, J. Atmos. Sol.-Terr. Phy., 51, 627-634, 1989.

Whitehead, J.: The formation of the sporadic E layer in the temperate zones, J. Atmos. Terr. Phy., 20, 49-58, 1961.

Wu, D. L., Ao, C. O., Hajj, G. A., de la Torre Juarez, M., and Mannucci, A. J.: Sporadic E morphology from GPSCHAMP radio occultation, J. Geophys. Res., 110, A01306, doi:10.1029/2004JA010701, 2005. 